\title{
It's a marathon not a sprint: the need for long-term monitoring of myocardial dysfunction in COVID-19
}

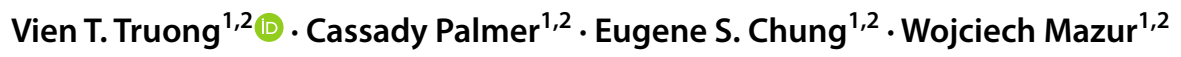

Received: 7 January 2022 / Accepted: 8 January 2022 / Published online: 27 January 2022

(c) The Author(s), under exclusive licence to Springer Nature B.V. 2022

Coronavirus Disease 2019 (COVID-19), caused by the severe acute respiratory syndrome coronavirus 2 (SARSCoV-2), is a pressing global public health issue. More specifically, the increased morbidity and mortality secondary to cardiac complications in COVID-19 has become concerning. Myocardial injury, defined by elevated troponin levels, is seen in up to $20-30 \%$ of patients hospitalized with COVID19 [1]. However, the exact mechanism of myocardial injury in COVID-19 has yet to be fully elucidated and is likely multifactorial. Furthermore, the true incidence of COVID19 related myocarditis has not been determined. Preexisting cardiovascular conditions, thrombotic events, hypoxemic pulmonary vasoconstriction, cytokine storm, increased pulmonary vascular resistance, endotheliitis, myocardial inflammation, and direct viral damage has been associated with COVID-19 related myocardial dysfunction [2-5].

Two-dimensional speckle tracking echocardiography (2D-STE) has been used to detect subclinical left ventricular (LV) dysfunction in various cardiopulmonary diseases, and significant changes can be seen prior to a detectable reduction in left ventricular ejection fraction (LVEF). It has been well established that decreased myocardial strain measured by 2D-STE is linked to worse outcomes in multiple clinical scenarios [6]. Recent data using 2D-STE have demonstrated a high prevalence of myocardial dysfunction in COVID-19 patients, which is associated with mortality independent of clinical and biomarker parameters [7]. A recent systematic review showed that more than half of COVID-19 survivors experienced a broad array of pulmonary and extra-pulmonary clinical manifestations 6 months after recovery [8]. However, little is known about possible residual myocardial

Vien T. Truong

vien.truong@thechristhospital.com;

thanhvientruong1988@gmail.com

1 The Heart and Vascular Center, The Christ Hospital Health Network, 2139 Auburn Ave, Cincinnati, OH 45219, USA

2 The Lindner Research Center, Cincinnati, OH, USA impairment, and whether there may be a myocardial culprit responsible for prolonged shortness of breath, chest pain, and fatigue following recovery from COVID-19.

In this issue of the Journal, Tryfou et al. [9] report their findings from a prospective cohort study of 100 recovered COVID-19 patients (mean age of $47.2 \pm 9.1$ years) with preserved LVEF. These patients were divided into two groups: The first group consisted of 67 patients who were hospitalized, and the second group included 33 patients with the milder disease who were treated as outpatients. In addition, a control group was constructed for comparison. A comprehensive evaluation of echocardiography with 2D-STE was performed after a minimum of 30 days from the initial diagnosis for the outpatients and 10 days after their discharge for the hospitalized patients. The mean time of performed echocardiography was $33.28 \pm 9.4$ days after the diagnosis of COVID-19. Compared to controls, cardiovascular risk factors including hypertension, hyperlipidemia, and diabetes mellitus were less prevalent in the COVID-19 cohort. Other baseline clinical characteristics did not differ significantly between the two groups. Of note, LV chamber dimensions, volumes, and ejection fraction $(59.22 \pm 3.72 \%$ vs. $60.14 \pm 3.19 \%, p=0.187$ ) were comparable between the COVID group and controls. However, left ventricular global longitudinal strain (LVGLS) was significantly reduced compared to the control group $(-18.47 \pm-2.4 \%$ vs $-21.07 \pm-1.76 \%, \mathrm{p}<0.0001)$. The reduced LVGLS occurred in both cohorts (outpatients and hospitalized) but to a greater degree in the latter. Furthermore, regional strain analysis revealed posterior and lateral longitudinal strain values were markedly impaired in both hospitalized and nonhospitalized patients. Regarding right ventricular impairment in COVID-19, the authors report that right ventricular global longitudinal strain (RVGLS) was significantly lower in the hospitalized group when compared to the control group $(-18.17 \pm-3.32$ vs. $-26.03 \pm-4.55, \mathrm{p}<0.0001)$. No significant correlation of LVGLS and RVGLS with high sensitivity cardiac troponin I and D-dimer were found. 
The main finding of this study was that despite demonstration of preserved LVEF, subclinical biventricular dysfunction persisted following COVID-19. Tangen et al. also reported LVGLS to be reduced in $15 \%$ of patients measured 3 months after hospitalization [10]. Interestingly, in agreement with previous data, the current study did not find a statistically significant association between reduced myocardial function and elevated high sensitivity cardiac troponin levels [10]. Similarly, a multicenter, prospective cohort study showed that there was evidence of persistent adverse ventricular remodeling in nearly one-third of the patients [11]. Cardiovascular magnetic resonance imaging known for its high accuracy for functional assessment further reinforces evidence of myocardial impairment in patients recently recovered from COVID-19 [12]. Importantly, the current study is one of the first to highlight regional subclinical dysfunction in patients recovering from COVID-19. The authors add to the current medical knowledge of LV strain in COVID-19 by highlighting the unique features of regional dysfunction involving the posterior and lateral segments. The regional wall motion abnormalities in posterior and lateral segments are similar to that of viral myocarditis in general [13], perhaps supporting the possibility of direct viral injury to the myocardium in COVID-19. Additionally, it is important to emphasize that a recently published paper showed in a community-based cohort, subclinical myocardial dysfunction was associated with an increased incidence of heart failure later in life [14]. This novel finding raises concerns for patients recovering from COVID-19 with a subclinical myocardial dysfunction who may develop heart failure over time.

This study has several limitations worth noting. First, this is a single-center study with a relatively small sample size. Second, an association of residual myocardial impairment with clinical outcomes is not reported in this study. Nonetheless, the current study by Tryfou et al. [9] has potential clinical implications regarding the importance of myocardial functional assessment in patients who have recovered from COVID-19. A comprehensive LV and RV functional assessment following COVID-19 using 2D-STE is warranted and should be tested in a larger cohort, and therapies tailored for myocardial dysfunction will need to be determined.

\section{Declarations}

Conflict of interest The authors have no conflicts of interest to declare.

\section{References}

1. Mitrani RD, Dabas N, Goldberger JJ (2020) COVID-19 cardiac injury: implications for long-term surveillance and outcomes in survivors. Heart Rhythm 17(11):1984-1990

2. Varga Z, Flammer AJ, Steiger P, Haberecker M, Andermatt R, Zinkernagel AS, Mehra MR, Schuepbach RA, Ruschitzka F, Moch
H (2020) Endothelial cell infection and endotheliitis in COVID19. Lancet 395(10234):1417-1418

3. Xu Z, Shi L, Wang Y, Zhang J, Huang L, Zhang C, Liu S, Zhao P, Liu H, Zhu L, Tai Y, Bai C, Gao T, Song J, Xia P, Dong J, Zhao J, Wang FS (2020) Pathological findings of COVID-19 associated with acute respiratory distress syndrome. Lancet Respir Med $8(4): 420-422$

4. Basso C, Leone O, Rizzo S, De Gaspari M, van der Wal AC, Aubry MC, Bois MC, Lin PT, Maleszewski JJ, Stone JR (2020) Pathological features of COVID-19-associated myocardial injury: a multicentre cardiovascular pathology study. Eur Heart J 41(39):3827-3835

5. Liu PP, Blet A, Smyth D, Li H (2020) The science underlying COVID-19: implications for the cardiovascular system. Circulation 142(1):68-78

6. Smiseth OA, Torp H, Opdahl A, Haugaa KH, Urheim S (2016) Myocardial strain imaging: how useful is it in clinical decision making? Eur Heart J 37(15):1196-1207

7. Li R, Wang H, Ma F, Cui GL, Peng LY, Li CZ, Zeng HS, Marian AJ, Wang DW (2021) Widespread myocardial dysfunction in COVID-19 patients detected by myocardial strain imaging using 2-D speckle-tracking echocardiography. Acta Pharmacol Sin 42(10):1567-1574

8. Groff D, Sun A, Ssentongo AE, Ba DM, Parsons N, Poudel GR, Lekoubou A, Oh JS, Ericson JE, Ssentongo P, Chinchilli VM (2021) Short-term and long-term rates of postacute sequelae of SARS-CoV-2 infection: a systematic review. JAMA Netw Open 4(10): 2128568

9. Tryfou ES, Kostakou PM, Chasikidis CG, Kostopoulos VS, Serafetinidis II, Ferdianaki EK, Mihas C, Olympios CD, Kouris NT (2021) Biventricular myocardial function in Covid-19 recovered patients assessed by speckle tracking echocardiography: a prospective cohort echocardiography study. Int J Cardiovasc Imaging 23:1-9

10. Tangen J, Aukrust P, Barratt-Due A, Skulstad H, Edvardsen T (2021) Reduced cardiac function by echocardiography in a minority of COVID-19 patients 3 months after hospitalization. J Am Soc Echocardiogr 7:S0894-7317(21)00816-6

11. Moody WE, Liu B, Mahmoud-Elsayed HM, Senior J, Lalla SS, Khan-Kheil AM, Brown S, Saif A, Moss A, Bradlow WM, Khoo J, Ahamed M, McAloon C, Hothi SS, Steeds RP (2021) Persisting adverse ventricular remodeling in COVID-19 survivors: a longitudinal echocardiographic study. J Am Soc Echocardiogr 34(5):562-566

12. Puntmann VO, Carerj ML, Wieters I, Fahim M, Arendt C, Hoffmann J, Shchendrygina A, Escher F, Vasa-Nicotera M, Zeiher AM, Vehreschild M, Nagel E (2020) Outcomes of cardiovascular magnetic resonance imaging in patients recently recovered from coronavirus disease 2019 (COVID-19). JAMA Cardiol 5(11):1265-1273

13. Kostakou PM, Kostopoulos VS, Tryfou ES, Giannaris VD, Rodis IE, Olympios CD, Kouris NT (2018) Subclinical left ventricular dysfunction and correlation with regional strain analysis in myocarditis with normal ejection fraction. A new diagnostic criterion. Int J Cardiol 259:116-121

14. Reimer Jensen AM, Zierath R, Claggett B, Skali H, Solomon SD, Matsushita K, Konety S, Butler K, Kitzman DW, BieringSorensen T, Shah AM (2021) Association of left ventricular systolic function with incident heart failure in late life. JAMA Cardiol 6(5):509-520

Publisher's Note Springer Nature remains neutral with regard to jurisdictional claims in published maps and institutional affiliations. 